\section{Ensaio} Essay

\title{
A teoria das cores de Goethe e sua crítica a Newton
}

Goethe's theory of colors and his criticism

of Newton

\section{NATHALY BARBOZA DE BRITO}

Centro Federal de Educação Tecnológica Celso Suckow da Fonseca | CEFET/RJ

\section{JOSÉ CLAUDIO DE OLIVEIRA REIS}

Centro Federal de Educação Tecnológica Celso Suckow da Fonseca | CEFET/RJ

Universidade do Estado do Rio de Janeiro | UERJ

\section{Introdução}

0 presente ensaio pretende apresentar a teoria das cores de Goethe e a sua a crítica à visão newtoniana de interpretar os fenômenos óticos, particularmente os associados às cores. 0 conhecimento dessa crítica goetheana representa uma boa oportunidade para apresentar a estudantes da escola básica uma outra visão sobre a natureza, possibilitando, desta forma, uma visão mais crítica e rica sobre a produção do conhecimento científico. ${ }^{1}$ Ainda que a proposta de Goethe para a teoria das cores não tenha saído vencedora no campo científico é importante a sua discussão com os alunos para que a apropriação da ciência não seja meramente instrumental. ${ }^{2} 0$ pensamento goetheano insere-se numa crítica maior empreendida pela Naturphilosophie à forma de produzir conhecimento herdeira do lluminismo. ${ }^{3}$

Sendo assim, apresentaremos a forma como Goethe analisou os fenômenos luminosos, assim como as suas motivações filosóficas para a construção de sua teoria para a luz e as cores. Vale também destacar que, ainda que não tenha sido vitorioso, o pensamento de Goethe, compondo as ideias da Naturphilosophie, vai deixar frutos para 0 pensamento científico do século XIX. Por exemplo, o desenvolvimento do princípio de conservação de energia está repleto de filósofos naturais que atuaram a partir de princípio que podemos identificar com a Naturphilosophie. ${ }^{4}$

\section{Goethe e a construção de sua visão de mundo}

Um dos críticos da teoria de Isaac Newton foi o poeta e pensador alemão Johann Wolfgang von Goethe (17491832). Em seu livro Doutrina das Cores, de 1810, Goethe contrapõe-se à visão de Newton sobre o fenômeno da luz e das cores. Esta contraposição, no entanto, não baseava-se na defesa de um modelo ondulatório para a luz. Goethe buscou demonstrar, em sua teoria, alguns aspectos subjetivos que a teoria de Newton não contemplava. 
Goethe nasceu em Frankfurt, Alemanha, em 28 de agosto de 1749. Apesar de ter se formado em direito, foi um escritor com grandes incursões pela ciência durante sua vida, em áreas como a física e a biologia. Passou a se dedicar à literatura, sua grande paixão, produzindo romances, peças de teatro, poemas e tratados nas áreas de literatura e ciências. 0 artista dialoga tanto com ideias discutidas no campo da estética literária, quanto das ciências e da filosofia. Seus escritos são capazes de se relacionar com a produção intelectual de seu tempo.

0 poeta alemão reuniu em si a criatividade poética e a pesquisa científica, utilizando-se da arte para a compreensão do mundo, da mesma forma que é realizado, ainda que com maior rigor, pela ciência. Para o poeta, arte e ciência teriam uma relação muito íntima. Em seu pensamento a arte parecia tão objetiva quanto a ciência, de modo que a visão artística de Goethe encontrava-se complementada pela visão cientifica. ${ }^{5}$ Para que seja possível compreender o contexto de criação da teoria das cores, bem como as concepções pessoais que nortearam a sua construção, é importante conhecer o meio social e as ideias que eram disseminadas à época de Goethe.

Goethe iniciou seus estudos literários no período de 1768-1770, com dezenove anos, em Frankfurt, enquanto recuperava-se de uma provável tuberculose. Na casa de seu pai, o jovem poeta se dedicou à leitura de diversas obras, aproveitando-se de uma biblioteca com mais de cinco mil volumes. Dentre suas leituras encontrava-se uma diversidade de escritos que perpassavam filósofos gregos, literatura nórdica, história da arte, literatura e ciência. Além desta leitura, alguns nomes de tradição mística, ou que de alguma forma embutiam o misticismo em suas obras, foram alvo da curiosidade do jovem enfermo, tais como Giordano Bruno (1548-1600), Paracelso (1493-1541) e Agrippa de Nettesheim (1486-1535). ${ }^{6}$

0 contato com o conhecimento produzido na Idade Média forneceu ao poeta uma postura ambivalente com relação à interpretação dos fenômenos da natureza. Ao mesmo tempo em que adotava uma visão materialista e investigativa, também era capaz de interpretar a natureza como uma expressão viva da criação. Através de Giordano Bruno, Goethe adquiriu uma ideia de universo infinito, vagamente baseada na noção copernicana do sistema celeste.?

0 curso do século XVIII levou à propagação das ideias iluministas e consequentemente a um distanciamento da metafísica e dos conceitos religiosos, especialmente na Europa. No entanto, Kestler aponta que o lluminismo não se apresentava como um ideal homogeneamente difundido. Desta forma, conviviam as mais diversas tendências, até mesmo aquelas fundamentadas em ideais religiosos. ${ }^{8}$

Contemporâneas a Goethe, duas tendências para investigação de fenômenos da natureza e ligadas às crenças religiosas eram difundidas, a emanentista e a imanentista. Estas tendências diferenciam-se através de suas ideias defendidas com relação à compreensão de mundo, sendo que a emanentista partia do princípio de que o mundo como um todo seria uma espécie de reflexo ou assinatura de Deus, enquanto os defensores da tendência imanentista acreditavam que o mundo por si só era divino na total autonomia de suas leis, não dependendo de um todo. Esta visão estaria voltada para um tipo de investigação baseada na harmonia dos fenômenos da natureza, fundamentava-se nos conceitos filosóficos de Spinoza (1632-1677) e Giordano Bruno. Goethe, portanto, baseia seu ideal de investigação da natureza na concepção imanentista. ${ }^{9}$

Partindo desse contexto, Goethe assume uma postura analítica e ao mesmo tempo filosófica com relação à natureza. Neste sentido, o poeta julga que os fenômenos, em toda sua magnitude, não podem ser conhecidos por completo, mas cabe ao homem tentar conhecê-los através de suas partes. 0 homem como sujeito ativo e que encontra-se no meio dos efeitos causados pelos fenômenos não deve deixar de questionar-se acerca dos mesmos. Na concepção de Goethe, este seria o caminho para que o homem, um ser finito e limitado, fosse capaz de chegar o mais próximo possível da perfeição, ou seja, através da busca pelo conhecimento da natureza (infinita)..$^{10}$

Sendo assim, Goethe considerava que o conhecimento profundo da natureza, bem como dos fenômenos que a formam, constitui uma grande vantagem ao artista, de modo que sua arte será capaz de captar as minúcias da natureza e descrevê-la em sua totalidade. A reprodução artística da natureza, segundo Goethe, não deveria limitar-se à reprodução fiel do real. Representar a natureza, portanto, deveria implicar no seu conhecimento e na sua compreensão enquanto matriz geradora e producente..$^{11}$ 
Na busca pela elucidação dos fenômenos, Goethe afirma que por mais que todas as ideias e concepções envolvidas pareçam complexas, todas elas podem ser esquematizadas e simplificadas através de esboços e desenhos precisos, 0 invisível não era contemplado em suas teorias. No entanto, o poeta considerava o fenômeno em si como um veículo para a sua própria compreensão através de suas partes. Se não é possível conhecer o todo (fenômeno), é possível obter uma espécie de dedução através de suas partes. Nesse sentido, a percepção da natureza deveria ser como ela própria, dinâmica e capaz de acompanhar seu contínuo devir. ${ }^{12}$

Além de concepções filosóficas, a troca de ideias com os mais diversos membros da comunidade científica da época também contribuiu para construir o conhecimento e a visão de mundo de Goethe. Ainda durante seu período como estudante de direito (1765-1768), o poeta passou a interessar-se também pela investigação científica através do conhecimento dos estudos de Carolus Linnaeus (Lineu) (1707-1778) sobre plantas, a História Natural do conde de Buffon (1707-1788), entre outros. Durante toda sua vida, Goethe manteve correspondência com cientistas de sua época, como o botânico Karl Friedrich Phillipp von Martius (1794-1868), que integrou a comitiva da arquiduquesa austríaca Leopoldina em sua vinda para o Brasil, e o naturalista Alexander Humboldt (1759-1859). Posteriormente, Goethe ainda incursiona pelos ramos da mineralogia e geologia, com importantes trabalhos na área, sendo eleito presidente da Sociedade Mineralógica de Jena na Alemanha. ${ }^{13}$

Sob influência de seus estudos na área de anatomia humana, osteologia e zoologia, Goethe apoia o princípio de que existe um forte parentesco entre os homens e os animais, o que era negado veementemente por importantes filósofos da época, como Immanuel Kant (1724-1804). Partindo desta concepção o poeta chega a algumas ideias evolucionistas diante de seus estudos sobre o osso intermaxilar, comum ao homem e aos demais vertebrados. Em sua interpretação, a natureza havia criado todos os seres vivos segundo um modelo fundamental de organização. ${ }^{14}$

Os estudos de Goethe sobre botânica também partem do princípio da existência de um modelo fundamental construído pela natureza. Sendo assim, o poeta busca encontrar na variedade das formas vegetais, uma forma primordial. No campo da botânica, torna-se nítida a busca de Goethe por uma essência geradora. Durante muitos anos o poeta buscou incansavelmente por uma planta primordial capaz de gerar todas as demais. Esta planta primordial seria portadora da essência geratriz de todas as outras, deveria ser, portanto, a mais simples dentre elas, pois as características posteriores, como coloração ou tamanho, seriam adquiridas posteriormente, imprimindo as peculiaridades capazes de diferenciar todas as plantas. Em sua busca, Goethe procurava por "algo" que faria com que determinado ser presente na natureza se tornasse uma planta, ou seja, a sua essência. De acordo com este fundamento, Goethe baseia o princípio de metamorfose, que seria equivalente a uma transição entre as formas que as plantas vão adquirindo durante seu crescimento, ou seja, as plantas seriam capazes de produzir uma parte através da outra. ${ }^{15}$

0 conceito de metamorfose é estendido para todos os seres vivos. Nesta ideia, os seres seriam dotados de uma essência, ou alma, porém, ao longo de sua existência poderiam se modificar, adquirindo outras características, mas sem nunca perder a sua essência. Esta visão de mundo construída pelo poeta influencia diretamente em sua visão de ciência e na compreensão dos mais diversos fenômenos da natureza, tendo em vista que o conceito de metamorfose será a base para a maioria de suas interpretações.

Para que seja possível compreender as interpretações que Goethe fará sobre a luz e as cores, especialmente sobre o fenômeno da decomposição, é preciso ressaltar alguns aspectos sobre sua teoria da metamorfose. Para Goethe as formas primordiais compõem todos os elementos da natureza, como as plantas, ou os animais, ou até mesmo a luz. A forma primordial, ou a essência que constitui todas as coisas, tem como importante característica a mudança, ou metamorfose, no entanto, a metamorfose ocorre sempre seguindo uma mesma regra: todas as formas evoluem do mais simples para o mais complexo. ${ }^{16}$

Partindo desta concepção, é possível compreender a dificuldade de aceitação da teoria newtoniana por parte do poeta. A experimentação realizada por Newton demonstra que a luz branca, mais complexa, poderia ser decomposta nas demais cores do espectro visível, mais simples. Deste modo, a luz passaria de um estado mais complexo para outro mais simples, o que estaria em completo desacordo com a visão de ciência de Goethe. 
Podemos perceber também através das ideias construídas por Goethe que a mobilidade entre as formas da natureza é um conceito muito pertinente para elucidar alguns fatos que o poeta observa ao seu redor. Sendo assim, é possível compreender que na concepção goetheana a natureza adota a transição ou metamorfose para mover-se entre os mais diversos estágios de um fenômeno. Além disso, através da ideia de metamorfose, é possível também compreender a concepção que Goethe insere em sua teoria de que as cores seriam derivadas de um processo de transição entre 0 claro e 0 escuro.

Outra característica subjetiva que permeia as concepções de Goethe são as leis de polaridade e de intensificação. Neste caso, 0 conceito de polaridade pertence à matéria e 0 da intensificação ao espírito e ambos atuariam conjuntamente, sendo assim, é possível compreender que para Goethe os contrários como luz e sombra não constituem dualidades antagônicas, mas 0 anverso e o reverso de uma mesma unidade polarizada. ${ }^{17}$

Ao analisarmos a teoria das cores sob a perspectiva das concepções pessoais nas quais Goethe estaria imerso, podemos compreender o quão improvável poderia lhe parecer a teoria newtoniana para a luz, pois a mesma não se insere nesta visão de mundo. 0 pensamento científico à época de Goethe estava fortemente baseado em pilares que rejeitavam quaisquer esquemas metafísicos para a interpretação de fenômenos da natureza e é nesta concepção que 0 pensamento newtoniano se insere. Goethe, em contrapartida, privilegia conceitos capazes de contemplar fatores metafísicos e subjetivos como as sensações causadas ao sentido da visão diante do fenômeno da luz, fundamentando sua teoria na transição das formas e nas analogias entre os fenômenos, construindo os mesmos através das leis de polaridade.

Os procedimentos experimentais realizados pelo poeta, ainda que sujeitos ao rigor científico, rejeitavam a instrumentalização e o uso de aparatos, com o objetivo de que seus leitores pudessem realizá-los e experimentar as sensações por eles causadas. Em sua concepção, os aparelhos utilizados em experimentos também poderiam falsificar a imagem do mundo. Estes aparelhos e os consequentes cálculos matemáticos eram responsáveis por violentar a natureza. ${ }^{18}$

As cores passaram a figurar na obra de Goethe quando este buscou conhecer melhor a escolha das cores na pintura. Em sua pesquisa com pintores não encontrou respostas satisfatórias, pois os mesmos sabiam apenas como aplicá-las e misturá-las, mas não se utilizavam de uma teoria que pudesse ser repassada. Daí então surge a necessidade de um estudo mais aprofundado sobre as cores. ${ }^{19}$

Obviamente outros artistas da época tiveram a necessidade de centralizar seus esforços em um estudo aprofundado das cores, no entanto, a peculiaridade de Goethe fica por conta de sua insatisfação com uma teoria que não pudesse ser descrita cuidadosamente e traduzida em conceitos. Tal insatisfação pode ser compreendida pelo espírito científico característico deste poeta.

\section{A construção de uma teoria das cores}

0 interesse de Goethe por uma teoria para as cores baseada em um cuidadoso sistema de regras intensifica-se no período de 1790 a 1791. Partindo das concepções filosóficas e referenciais que nortearam a visão de mundo adotada por ele é possível fazer uma leitura mais aproximada da concepção científica adotada pelo poeta ao construir sua crítica à teoria newtoniana.

Ao analisarmos a Doutrina das Cores, o estudo publicado por Goethe em 1810, percebemos que a chave para a compreensão dos fenômenos cromáticos encontra-se na subjetividade do sentido da visão, representada pelo olho humano. Essa maneira de interpretar os fenômenos não poderia ser diferente, tendo em vista que para o poeta o homem e a natureza estavam intrinsecamente ligados, uma vez que a natureza se revela aos nossos sentidos e sobre ela, e com base em nossas sensações, realizamos nossas observações e tiramos nossas conclusões. Ou seja, a chave para a solução dos mistérios que envolvem a natureza, encontra-se no próprio homem. Sendo assim, o sujeito e o objeto fazem parte da mesma construção. 
Partindo destes princípios podemos entender melhor em que se baseia sua divergência com Newton. A teoria goetheana busca sintetizar cor e luz como um fenômeno único capaz de se revelar aos nossos olhos e por eles ser interpretado, ao passo que Newton compreende que as cores derivam da luz. A leitura de Goethe acerca dos fenômenos ópticos o levou a uma conclusão repleta de inspiração poética, ao mesmo tempo em que centrava-se em suas concepções filosóficas. A luz deveria, portanto, ser observada a partir de sua completude que contemplava a luz e as cores em sua unidade.

Ao aprofundar-se na teoria newtoniana das cores, o espírito crítico do autor se mostra insatisfeito com a insuficiência de seu conteúdo. No entanto, Goethe se mostra concordante com alguns aspectos da mesma. Ele aceita plenamente o fato de que as cores estão ligadas à luz, no entanto ao associá-las, mantém sua característica poética afirmando que "as cores são ações e paixões da luz". ${ }^{20}$

0 poeta critica a teoria de Newton com base em suas peculiaridades artísticas e filosóficas, procurando criar sua própria teoria baseada fundamentalmente nas sensações. Esta peculiaridade na forma de observar a natureza norteia toda a teoria de Goethe, de modo que até mesmo os experimentos realizados levando em consideração uma rigorosa metodologia, baseada em argumentações científicas, têm sua interpretação fortemente vinculada a um caráter subjetivo.

Sua crítica à teoria newtoniana fundamenta-se na visão mecanicista de Newton para o fenômeno da luz, na qual, segundo ele, os "fenômenos inoportunos" à mesma eram "ligados e constrangidos artificialmente". ${ }^{21} \mathrm{~A}$ discordância fundamental entre as teorias se dava no ponto em que Goethe não acreditava que a luz poderia ser composta por cores mais escuras que ela própria, como afirmava Newton.

A teoria goetheana fundamenta-se no conceito de que a luz deve estar intimamente relacionada à visão. Apesar de sua forte crítica à teoria mecanicista, o próprio Goethe parece estar sob sua influência ao afirmar que luz e cores emergem quando os olhos sofrem um "choque mecânico" mediante a exposição à luz externa. ${ }^{22}$ Sendo assim, de acordo com a sua teoria, não enxergamos o mundo ao nosso redor a partir da atuação da luz sobre os corpos, mas principalmente através de sua ação sobre 0 olho humano. ${ }^{23}$

A formação das cores em sua teoria não leva em consideração a decomposição da luz branca conforme a teoria de Newton, mas a presença de luz e sombra além de sua mistura para a formação das cores primárias:

(...) luz e sombra, claro e escuro ou, para utilizar uma fórmula mais geral, luz e não-luz são requeridos para a produção da cor. Na luz surge para nós, em primeiro lugar, uma cor que chamamos amarelo, e outra, na escuridão, que designamos azul. Quando essas duas se misturam no seu estado mais puro, de modo que ambas se mantenham em perfeito equilíbrio, surge uma terceira cor que chamamos de verde. ${ }^{24}$

A teoria sobre a mistura de luz e sombra para a formação das cores, proposta por Goethe é muito semelhante às teorias propostas pelos antecessores de Newton que supunham que a luz era transformada ao passar por superfícies transparentes, como um prisma ou uma superfície colorida, sendo causada pela mistura da luz com a escuridão, de modo que pareceria colorida aos olhos.

Para corroborar sua ideia de mistura de luz e sombra, Goethe realizou alguns experimentos para compreender e demonstrar a atuação sobre o olho humano do que chama de Cores Fisiológicas. De acordo com sua interpretação estas cores devem ser chamadas de fisiológicas, pois estão relacionadas ao olho humano saudável e podem ser consideradas necessárias à visão. ${ }^{25}$

Um de seus experimentos consiste em uma pequena placa negra com um orifício de 3 polegadas, capaz de ser aberto e fechado e permitindo que a luz do Sol passe por ele e incida sobre uma superfície branca, projetando-se sobre esta superfície um círculo luminoso. Deste modo, a pessoa deveria olhar para este círculo iluminado e em seguida fechar o orifício e voltar o seu olhar para uma região sem iluminação. Esta sequência deveria realizar um efeito sob o olho do espectador, de modo que este enxergaria inicialmente uma imagem circular a sua frente, inicialmente sem cor, e pouco a pouco este se tornaria amarelo com uma borda púrpura ao seu redor. Esta borda iria, em seguida, se alargando e 
penetrando no círculo que se tornaria totalmente púrpura. Depois disso, a borda do círculo passaria a apresentar uma coloração azulada, penetrando no círculo até que o mesmo se tornasse totalmente azul. Por fim uma borda escura apareceria, tomando conta de toda extensão do círculo até que o mesmo se tornasse totalmente sem cor. ${ }^{26}$

É possível perceber que, através desse experimento, Goethe interpreta que as diferentes cores observadas surgiram em decorrência da mistura de luz e sombra colocadas como desencadeadoras do fenômeno. Goethe explica 0 processo da visão através da sobreposição de luz e não luz (escuridão) sobre a retina. De acordo com sua concepção, a retina ao encontrar-se submetida à luz ou à escuridão, encontra-se sob dois estados antagônicos.

Para demonstrar tal fenômeno, Goethe realiza um experimento muito simples utilizando-se de substâncias químicas. Tal experimento consiste em pintar cada degrau de uma escada branca com uma solução de azul de sulfato de cobre ou com uma solução amarela de dicromato de potássio. Ao observar do alto tal escada, nota-se que cada degrau inferior parece apresentar um tom mais forte de azul ou amarelo. Com este experimento Goethe buscou demonstrar que as cores não podem surgir a partir da decomposição da luz, mas da mistura que surge diante do claro e escuro. ${ }^{27}$

Quando nos encontramos de olhos abertos em um local sem qualquer iluminação, a retina encontra-se em seu estado natural, longe de qualquer forma de excitação sob a luz. Ao contrário, quando estamos em um lugar totalmente iluminado, nossos olhos são ofuscados pela luz e se tornam por certo tempo, incapazes de distinguir objetos iluminados. Deste modo, o poeta interpreta que a mistura desses dois estados sobre a retina, seria capaz de dar origem a toda diversidade cromática.

Naquilo que denominamos ver, a retina se encontra simultaneamente em estados diferentes e até opostos. A máxima claridade não ofuscante atua ao lado da escuridão total. Percebemos ao mesmo tempo todos os graus intermediários do claro-escuro e todas as determinações cromáticas. ${ }^{28}$

Goethe atribuiu à saúde e à natureza dos olhos o tempo de permanência da impressão causada ao observar uma luz muito intensa. Neste caso, o tempo dependeria do restabelecimento da retina, ao passar do claro para o escuro. Este tempo também estaria relacionado à energia da fonte luminosa observada, de modo que o Sol é a fonte que deixaria sua impressão na retina por mais tempo. Outros corpos perdurariam por mais ou menos tempo de acordo com a sua luminosidade. Em sua teoria, as imagens coloridas também poderiam causar efeito semelhante ao das luzes ofuscantes. No entanto, nesse caso, a imagem resultante após a observação de determinada cor, seria visualizada na cor complementar da primeira, de acordo com o círculo cromático que conhecemos.

Goethe relata que em um passeio no dia 19 de junho do ano de 1799, já ao anoitecer, ao observar um jardim de papoulas orientais na cor vermelha, foi possível enxergar próximo às flores algo como uma chama na cor verde-azulada. 0 poeta explica este fenômeno como sendo de cunho fisiológico. De acordo com sua análise, o crepúsculo seria 0 motivo pelo qual o olho estaria totalmente relaxado e sensível. Deste modo, a cor vermelha intensa da papoula seria capaz de evocar sua imagem complementar gerada sob o olho humano. ${ }^{29}$

0 autor complementa a narrativa de sua experiência dizendo ser capaz de reproduzi-la e fornecendo o caminho para quem desejar realizá-lo:

Se alguém quiser fazer essa experiência na natureza, será preciso que, andando pelo jardim, se exercite a olhar firmemente para as flores coloridas e, logo em seguida, para o caminho de areia, e assim verá a este salpicado de manchas da cor complementar. Essa experiência também pode ser bem sucedida sob um céu nublado e até mesmo num dia ensolarado, pois os raios de sol, ao intensificar a cor das flores, as tornam capazes de produzir a cor complementar numa intensidade suficiente para ser notada sob a luz ofuscante. As peônias produzem assim, um belo verde, as calêndulas, um vivo espectro azul. ${ }^{30}$

A Doutrina das Cores ressalta que os efeitos das cores complementares também podem ocorrer simultaneamente sobre a retina. Sendo assim, se uma imagem colorida se imprime em uma parte da retina, imediatamente a parte res- 
tante produz a cor correspondente de acordo com sua cor complementar. Para a visualização de tal fenômeno, Goethe propõe novamente um experimento. De acordo com o poeta, ao observarmos um pedaço de papel amarelo sobre uma superfície branca, a parte restante da retina não solicitada pela cor amarela é capaz de produzir imediatamente o violeta, sua cor complementar, sobre a superfície branca. Do mesmo modo, se alguns pedaços de papel branco forem dispostos sobre uma superfície amarela, seríamos capazes de observá-los como se estivessem revestidos por um tom violeta. ${ }^{31}$

Todos estes fenômenos cromáticos descritos por Goethe são explicados em sua teoria como uma propriedade intrínseca do olho humano, de modo que este órgão é capaz de evocar determinadas cores a partir do momento em que é estimulado. Tal comportamento se justificaria através da busca por uma harmonia na totalidade das cores.

Esses fenômenos são da mais alta importância, na medida em que nos indicam que as leis da visão constituem uma preparação necessária para se considerarem futuramente as cores. Neles o olho almeja uma totalidade contendo em si mesmo o círculo cromático. Azul e vermelho encontram-se no violeta, complementar ao amarelo. No laranja, correspondente ao azul, encontram-se o amarelo e o vermelho (......32

A sensação que as cores podem causar, fazendo com que determinados objetos pareçam menores ou maiores, também foi um dos pontos contemplados pela Doutrina das Cores de Goethe. Para demonstrar tal efeito, Goethe usou a ideia de dois círculos do mesmo tamanho, um deles na cor branca sobre um fundo preto e outro preto sobre um fundo branco.

De acordo com sua conclusão, esses círculos, quando observados simultaneamente, passam a impressão de que possuem tamanhos diferentes. Temos a impressão, ao observá-los, de que o círculo preto sobre o fundo branco é aproximadamente um quinto menor que o outro, sendo assim, se a imagem preta for aumentada nessa proporção, eles parecerão iguais. ${ }^{33}$
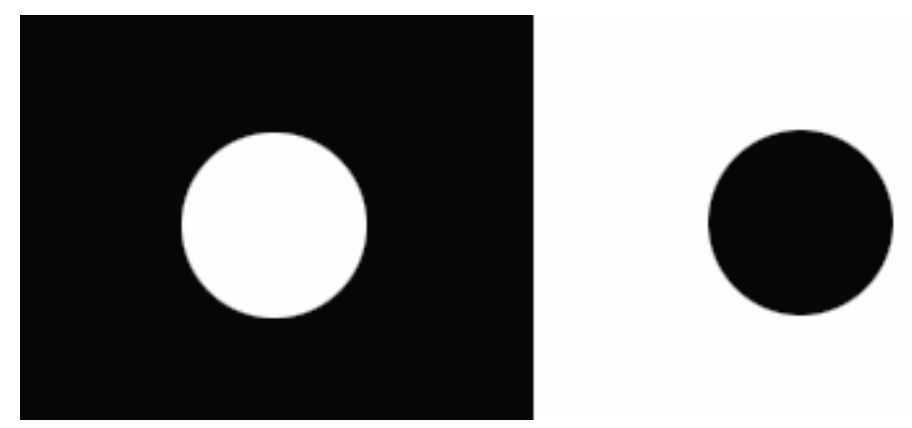

Figura 1 - Círculos com o mesmo tamanho pintados em cores diferentes (Fonte: autoria própria)

Goethe ressalta que esta propriedade das cores teve aplicações na astronomia ao levar o astrônomo dinamarquês Tycho Brahe (1546-1601) à conclusão de que a lua em conjunção com o Sol, a lua nova (mais escura), parece um quinto menor do que em oposição, a lua cheia (mais clara). ${ }^{34}$

A teoria goetheana classifica as cores através da forma como elas ocorrem, portanto, como vimos anteriormente, as cores fisiológicas são aquelas produzidas na retina, através de propriedades natas do olho humano. Outra categoria descrita em sua teoria, e relevante para este trabalho, é a categoria das cores físicas. Estas são definidas por Goethe como sendo aquelas que têm sua origem através dos meios materiais incolores, podendo estes ser transparentes, turvos e translúcidos, ou ainda, completamente opacos. Estas cores, por sua vez, são produzidas no olho humano através de causas externas, ou seja, são produzidas fora do olho e são refletidas nele.

Este tipo de cor possui a característica de ser difícil de fixar, recebendo também alguns nomes como colores aparentes, fluxi, fugitivi, phantastic, falsi ou variantes. Estão diretamente relacionadas às cores fisiológicas, pois para as 
cores fisiológicas o fenômeno ocorre internamente, no olho, já as cores físicas podem ser estimuladas no olho através do meio em que se encontra, de modo que o fenômeno possa ser visto fora de nós.

Analisando a proposição de Goethe sobre as cores físicas, podemos compreender que, para estas, o olho humano não possui atuação própria, apenas é o sujeito responsável pela recepção e interpretação de um fenômeno externo a si mesmo.

Os meios incolores recebem especial atenção na categoria das cores físicas por serem responsáveis por criar diferentes condições para a luz. Goethe classifica três formas segundo as quais a luz pode ser condicionada pelo meio:

- Fenômenos catóptricos: ocorrem quando a luz é refletida a partir da superfície de um meio;

- Fenômenos parópticos: ocorrem quando a luz é refletida na borda de um meio;

- Fenômenos dióptricos: ocorrem quando a luz atravessa um meio material transparente ou translúcido.

Em sua Doutrina das Cores Goethe procura discorrer especialmente sobre as cores provenientes dos fenômenos dióptricos. A influência do meio era de essencial importância na teoria do artista. Goethe classifica esse tipo de cor, dependente do meio, como cores dióptricas. As cores dióptricas dependeriam de um meio incolor, de tal forma que luz e escuridão atuassem sobre o olho ou sobre superfícies postas diante dele. Este tipo de concepção assemelha-se à ideia proposta por Aristóteles de que a luz estaria associada ao meio material existente entre o observador e o objeto.

As cores dióptricas são classificadas em cores dióptricas de primeira classe e cores dióptricas de segunda classe.

\section{Cores dióptricas de primeira classe}

0 espaço seria uma propriedade inteiramente transparente, que seria o primeiro grau de turvação do meio. 0 branco seria a turvação completa. Do transparente ao branco opaco, as graduações seriam infinitas. Ao exemplificar os casos onde este tipo de fenômeno ocorre, Goethe cita as cores atmosféricas:

O Sol, visto através de uma certa quantidade de vapores, apresenta um disco amarelo. (...) Na névoa, o Sol, com todas as nuvens que o circundam, parece vermelho rubi (...). O vermelho da aurora e do crepúsculo surge pelo mesmo motivo. Brilhando através de uma intensa massa de vapores, o sol se anuncia através de um vermelho. À medida que desponta, o brilho se torna cada vez mais claro e amarelo. Se a escuridão do espaço infinito é vista através de vapores atmosféricos iluminados pela luz do dia, surge a cor azul. Durante o dia, o céu visto do alto das montanhas, é azul-real, pois apenas vapores esparsos pairam diante do escuro espaço infinito. Ao se descer em direção ao vale, o azul se torna mais claro, até que finalmente, em certas regiões e devido a vapores crescentes, ele se converte num azul tirante a branco. ${ }^{35}$

\section{Cores dióptricas de segunda classe}

Para caracterizar este tipo de cor, Goethe assume uma postura bastante subjetiva, com a finalidade de centralizar tal fenômeno no ser humano e em sua própria interpretação. A relação entre o homem e o fenômeno é colocada como ponto central deste tipo de cor. Para que as condições externas fossem fielmente conhecidas pelo indivíduo, seria necessário que o mesmo apresentasse uma perfeita saúde de seus sentidos.

Nesta categoria das cores dióptricas, Goethe inclui também o fenômeno da refração: 
Objetos vistos através de meios mais ou menos opacos não aparecem para nós no lugar que deveriam estar pelas leis da perspectiva. Nisso residem os fenômenos dióptricos de segunda classe. ${ }^{36}$

Para este fenômeno Goethe apresenta o que ele chama de aspectos objetivos e subjetivos que são demonstrados através de dois experimentos. 0 experimento de cunho objetivo relata um recipiente cúbico vazio cujo um feixe de luz 0 atinge na diagonal. Em seguida Goethe indica que seja colocada água lentamente no recipiente e o observador poderá perceber que 0 raio luminoso aparentemente se deslocará em relação à sua trajetória inicial. ${ }^{37}$

A experiência subjetiva descrita pelo poeta será responsável por demonstrar a sensação causada no olho humano pelo fenômeno físico da refração. Para isto o observador deverá colocar o olho na posição do Sol, sendo capaz de ver sobre a borda do recipiente e na diagonal, a parede interna, sem, no entanto, ver o fundo do recipiente. Ao verter água sobre o recipiente, o observador será capaz de ver o fundo do mesmo. Este fenômeno é nomeado por Goethe como elevação. ${ }^{38}$

Analisando estes experimentos e a forma como o poeta os interpreta, percebemos um importante ponto de sua teoria que é a consideração das impressões subjetivas no que se refere aos fenômenos físicos, colocando o homem como agente participante dos mesmos.

\section{As cores químicas}

Por último, Goethe designa mais uma forma de cor, a das cores químicas. Sobre este tipo de cor podemos interpretá-las como as cores inerentes aos objetos, sendo definidas na Doutrina das Cores como:

(...) as cores estimuladas em certos corpos, mais ou menos fixas, que neles se intensificam, deles podem ser extraídas e transmitidas a outros corpos, às quais, por esta razão, atribuímos uma certa qualidade imanente. Em geral, caracterizam-se pela durabilidade. ${ }^{39}$

Para o surgimento das cores químicas, Goethe recorre novamente à relação entre o branco e o negro, de modo que as demais cores surgiriam a partir destas. 0 branco, como dito anteriormente, seria a turvação pura e completa, já o preto não surgiria de maneira tão primordial, este seria encontrado na natureza através da combustão de materiais orgânicos e do carvão. As cores seriam, portanto, estimuladas no preto e no branco. Por exemplo, o amarelo surgiria através do escurecimento do branco e o preto, ao clarear-se, se tornaria azul. As cores também poderiam ser intensificadas desde o mais leve amarelo ao mais intenso tom de vermelho.

A luz, ou a ausência dela, também poderia ser responsável pela intensificação da cor. Isto poderia ocorrer, por exemplo, ao depositar um líquido amarelo puro em um recipiente de porcelana branco, é possível observar que quanto mais próximo do fundo, o líquido parecerá mais avermelhado, em contrapartida, quando colocamos um recipiente contendo um líquido azul escuro exposto à luz do Sol, o mesmo é capaz de apresentar uma coloração violeta. É possível perceber que os fenômenos de absorção e reflexão da luz são interpretados, neste caso, como uma mistura entre a luz ou a escuridão e o material. Sendo assim, as cores possuem certa mobilidade e podem se alterar a partir de sua interação com os fatores externos.

Uma interessante observação acerca da relação entre a luz e as cores químicas na teoria de Goethe é a analogia que o poeta realiza entre a luz, o ar e a água no que diz respeito à interação destes com uma superfície colorida. De acordo com a sua interpretação, a ação da luz sobre os materiais coloridos seria similar àquela que ocorre com 0 ar e a água, sendo assim, a luz atuaria sobre a superfície material, desgastando-a e consequentemente, deixando-a mais clara aos nossos olhos.

É possível perceber que Goethe não faz menção à possibilidade da luz branca ser composta por outros feixes, pois esse tipo de mistura, em sua concepção, não seria capaz de constituir a luz branca. Mesmo não concordando com 
o fato de que as cores seriam decorrentes da decomposição da luz, Goethe realiza experimentos utilizando prismas e corrobora com a existência das três cores-luz primarias. No entanto, os experimentos realizados com o prisma pelo próprio Goethe não serviram para convencer-Ihe de que a luz poderia ser decomposta em cores mais escuras do que a própria luz, pois este fato não se enquadrava em sua concepção prévia ao experimento. ${ }^{40}$

Para compreender os esforços de Goethe ao explicar o fenômeno prismático utilizando a ideia da mistura de luz e não-luz, é necessário entender que a luz era compreendida por Goethe como um "fenômeno primordial", neste sentido, supunha que não deveria atribuir-lhe nada por trás nem além dele, sendo assim, a luz como a vemos não deveria ser decomposta em partes, este tratamento resultaria em "erros notáveis" ${ }^{41}$ Ao compreender desta forma, Goethe atribui ao fenômeno da luz um caráter essencialmente filosófico:

Que o investigador da natureza deixe o fenômeno primordial em sua eterna quietude e magnificência que o filósofo possa acolhê-lo em seu próprio âmbito, e descobrirão que não se trata de casos particulares, rubricas gerais, opiniões e hipóteses, mas de um nobre material, um fenômeno primordial básico, legado para trabalhos e estudos futuros. ${ }^{42}$

Na teoria goetheana, no entanto, não há negação do fenômeno físico, porém o fenômeno como compreendido pela ciência nada tem a ver com a sensação que o mesmo causa, e esta sensação por sua vez não é contemplada nas teorias cientificas. É neste ponto que o poeta constitui sua teoria.

A luz na teoria de Goethe seria, portanto, "uma sensação comum a todas as cores"43. Somente compreendendo sua própria definição do fenômeno é que podemos compreender sua teoria. Diante da concepção sensorial de luz, nem mesmo a mudança do paradigma corpuscular, atribuído aos mecanicistas, para o ondulatório, foi capaz de fazer com que Goethe sentisse a necessidade de alterar sua teoria, pois esta também poderia ser conciliada com suas concepções a respeito da essência da cor. ${ }^{44}$

\section{Considerações finais}

Com o que discutimos anteriormente é possível compreender, portanto, que as teorias de Goethe e Newton possuem uma relação, não necessariamente antagônica, mas de certo modo complementar, tendo em vista que a teoria goetheana contempla aspectos que não são compreendidos pela teoria de Newton, como a interpretação das cores a partir das sensações causadas. Devemos levar em consideração que estas teorias partem de visões de mundo completamente distintas, baseadas em suas próprias filosofias e derivadas da necessidade pessoal de ambos.

Estes aspectos da teoria de Goethe e Newton é importante para fazermos uma abordagem contextual do Ensino de Ciências em que o conhecimento da ciência não se basta em si mesmo, mas só ganha legitimidade na medida em que permite maior reflexão e compreensão do mundo onde a ciência é construída. Uma leitura cientifica da cultura, bem como uma leitura cultural da ciência são fundamentais para uma formação cidadã de estudantes da escola básica.

\section{Notas e referências bibliográficas}

Nathaly Barboza de Brito é mestre em Ciência, Tecnologia e Educação pelo Centro Federal de Educação Tecnológica Celso Suckow da Fonseca (CEFET/RJ). E-mail: nathaly.barboza@gmail.com.

José Cláudio de Oliveira Reis é doutor em História e Filosofia da Ciência pela COPPE/UFRJ, professor adjunto do Instituto de Física da Universidade do Estado do Rio de Janeiro (UERJ) e professor do Programa de Pós-Graduação em Ciência, Tecnologia e Educação do Centro Federal de Educação Tecnológica Celso Suckow da Fonseca - CEFET/RJ. E-mail: guerrareis@tekne.pro.br. 
REIS, José Claudio; GUERRA, Andreia; BRAGA, Marco. Ciência e arte: relações improváveis? História, Ciências, Saúde - Manguinhos, Rio de Janeiro, v. 13 (supl.), p. 71-87, 2006.

\section{5}

TALON, Ivan. Sobre a metafísica romântica e a construção do princípio de conservação da energia. Dissertação de mestrado, CEFET-RJ, 2015

CANEVA, Kenneth. Physics and Naturphilosophie: A reconnaissance. History of Science, v. 35, p. 35-106, 1997.

STEINER, Rudolf. A obra cientifica de Goethe. São Paulo: ed. São Paulo. 1984.

MOURA, Magali. Da magia a Kant: considerações sobre a relação de Goethe com a Filosofia. Matraga, n. 29, v. 18, p. 112-137, 2011.

Idem.

KESTLER, Izabela Maria Furtado. Johann Wolfgang von Goethe: art and nature, poetry and science. História, Ciências, Saúde - Manguinhos, v. 13, p. $39-54,2006$. Idem.

GUIDOTTI, Mirella. Imbricações entre Goethe e Kant: arte, natureza e sublime. Pandaemonium Germanicum, n. 17, p. 118-131, 2011.

MOURA, op. cit., 2011.

GUIDOTTI, op. cit., 2011.

KESTLER, op. cit., 2006.

\section{Idem.}

Idem.

Idem.

Idem.

Idem.

STEINER, op. cit., 1984.

GOETHE, Johann Wolfgang Von. Doutrina das Cores. São Paulo: Nova Alexandria, 1993, p. 35.

Idem.

Idem, p. 45.

GONÇALVES, Márcia Cristina Ferreira. Hegel leitor de Goethe: Entre a física da luz e o colorido da arte. Revista Eletrônica de Estudos Hegelianos. Ano 5, n. 8, p. 37-56, 2008.

24 GOETHE, op. cit., 1993, p. 47.

25 Idem.

26 GONÇALVES, op.cit., 2008.

27 Idem.

28 GOETHE, op. cit., 1993, p. 55.

29 Idem, p. 89.

30 Idem.

31 Idem, p. 69.

32 Idem.

33 Idem.

34 Idem.

35 Idem, p. 89.

$36 \quad$ Idem, p. 92

37 Idem.

38 Idem.

39 Idem, p. 101.

40 PEDROSA, Israel. Da cor à cor inexistente. São Paulo: Editora Senac São Paulo 2009, p. 67.

41 GOETHE, op. cit., 1993, p. 91.

42 Idem.

43 STEINER, op. cit., 1984, p. 169.

44 Idem.

[Recebido em Março de 2016. Aprovado para publicação em Outubro de 2016] 